Article

\title{
Astaxanthin Attenuates Fish Oil-Related Hepatotoxicity and Oxidative Insult in Juvenile Pacific White Shrimp (Litopenaeus vannamei)
}

\author{
Yingying Yu ${ }^{1,2,3}$, Yang Liu ${ }^{2}$, Peng Yin ${ }^{1}$, Weiwen Zhou ${ }^{1}$, Lixia Tian ${ }^{1}$, Yongjian Liu ${ }^{1}$, \\ Donghui $\mathrm{Xu}^{3}$ and Jin Niu ${ }^{1, *(\mathbb{D})}$ \\ 1 State Key Laboratory of Biocontrol, Institute of Aquatic Economic Animals and Guangdong Provincial Key \\ Laboratory for Aquatic Economic Animals, School of Life Science, Sun Yat-sen University, \\ Guangzhou 510275, China; yuyinyin1233@163.com (Y.Y.); peng.yin@hi.no (P.Y.); xszww@foxmail.com (W.Z.); \\ Lixiatian2002@163.com (L.T.); lsslyj@mail.sysu.edu.cn (Y.L.) \\ 2 Guangdong Key Laboratory of Animal Molecular Design and Precision Breeding, School of Life Science and \\ Engineering, Foshan University, Foshan 528225, Guangdong, China; 17303468530@163.com \\ 3 Laboratory of Traditional Chinese Medicine and Marine Drugs, Department of Biochemistry, Traditional \\ Chinese Medicine and Marine Drugs, School of Life Sciences, Sun Yat-sen University, Guangzhou 510275, \\ China; dongxugz@163.com \\ * Correspondence: gzniujin2003@163.com; Tel.: +86-0284110789
}

Received: 25 February 2020; Accepted: 7 April 2020; Published: 17 April 2020

\begin{abstract}
The present study investigated the effect of dietary astaxanthin (AX) on the growth performance, antioxidant parameters, and repair of hepatopancreas damage in Pacific white shrimp (Litopenaeus vannamei). To evaluate the hepatopancreas protective function of AX in shrimps, we compared the effect of five isonitrogenous and isoenergetic diets under oxidized fish oil conditions with varying AX levels during the 50-day experimental period. The formulated diets were as follows: (i) OFO (oxidized fish oil); (ii) OFO/AX150 (oxidized fish oil + AX150 mg/kg); (iii) OFO/AX250 (oxidized fish oil + AX250 mg/kg); (iv) OFO/AX450 (oxidized fish oil + AX450 mg/kg); and, (v) control group (fresh fish oil). Results showed that the oxidized fish oil with $275.2 \mathrm{meq} / \mathrm{kg}$ peroxide value (POV) resulted in a substantial decrease in the final body weight of $L$. vannamei $(P>0.05)$ and induced some visible histopathological alterations in the hepatopancreas. Growth performance was significantly higher in shrimps fed with the OFO/AX450 diet than those fed with the OFO diet $(p<0.05)$. However, no significant difference was observed when the OFO/AX450 diet was compared to the control diet containing fresh fish oil $(p>0.05)$. Moreover, shrimps under the OFO/AX450 diet displayed a significant improvement in hepatopancreatic health and showed a reduction of malondialdehyde (MDA) compared to those under the OFO diet $(p<0.05)$. Dietary AX improved the antioxidant capacity of L. vannamei by increasing the catalase (CAT) activity in the hemolymph. Acute salinity change test showed a higher shrimp survival rate under OFO/AX450 diet than the OFO diet $(p<0.05)$, suggesting that $\mathrm{AX}$ can contribute to enhanced stress tolerance. In conclusion, our data suggest that AX confers dose-dependent protection against OFO-induced oxidative insults and hepatopancreatic damage in shrimp.
\end{abstract}

Keywords: astaxanthin; oxidized fish oil; Litopenaeus vannamei; oxidative insult; hepatopancreas protection

\section{Introduction}

The marine carotenoid astaxanthin (AX) is naturally found in a wide variety of aquatic organisms, such as microalgae, crustaceans (crabs, lobsters, and shrimp), and fish (salmon and trout) [1,2]. AX has a hydrophobic polyunsaturated polar structure on both ends of the conjugated olefins structure, 
facilitating its precise positioning within cell membranes and circulating lipoproteins. In effect, AX exhibits a potent antioxidant function as a powerful scavenger of oxygen-free radicals, so as to decrease the oxidative stress and lipid peroxidation [3]. AX is renowned as a powerful antioxidant that has been reported to surpass those of $\beta$-carotene or lutein and even $\alpha$-tocopherol [4]. In crustaceans, some studies demonstrated that dietary astaxanthin could increase the total antioxidant capacity (TOC), improve growth performance [5-7], increase survival [8], and enhance resistance to different types of environmental stresses, including salinity stress [9], oxygen depletion stress [10] and high temperature stress [11]. Therefore, dietary astaxanthin, which is a remarkable antioxidant, could be used to improve the growth performance and enhance the stress tolerance of marine species.

Lipid peroxidation is the oxidative deterioration of polyunsaturated fatty acids (PUFAs) through a free-radical chain reaction. Lipid peroxide can damage the lipid-rich cell membranes of the organism [12]. Fish oil, which is rich in PUFAs, is necessary to maintain the cell membrane fluidity of aquatic animals. However, PUFAs are very susceptible to peroxidation to form toxic lipid hydroperoxides, the primary oxidation products, through a free radical related process. The unstable lipid hydroperoxides can decompose readily to fatty acid alkoxy [13] or break down to release a series of secondary oxidation products, such as aldehydes, ketones, alcohols, and carboxylic acids [14]. These by-products of oxidation are the primary source of unpleasant flavor and odor in decomposing marine organisms, as a result of the damage of cellular biomembranes and animal health deterioration $[15,16]$. Previous studies have shown that the use of oxidized oil in fish diet can delay development or survival by modulating hemoglobin concentration, and glycolytic activity, lipid peroxidation [17-20], and the deposition of $\alpha$-tocopherol [21]. In contrast, our understanding of the effects of lipid oxidation on crustacean species is limited. Koshio et al. (1994) reported that oxidized oil can result in growth reduction, reduced post-larval size, and poor health in Penaeus japonicas [22]. Laohabanjong et al. (2009) showed that the oxidation of fish meal lipid can result in abnormalities with haemocytic infiltration, atrophy of tubular epithelial, and nodule formation in tiger shrimp Penaeus monodon [23]. Wang et al. (2015) found that moderate and high oil oxidization can lower the survival and feeding efficiency of juvenile Chinese mitten crab Eriocheir sinensis [24]. Although oxidized fish oil has a negative effect on crustaceans, only a few studies have explored how to reduce the adverse impact of lipid peroxidation through diet management.

The Pacific white shrimp (Litopenaeus vannamei) is the most commonly cultured crustacean in South China. In recent years, the deteriorating environments have seriously affected shrimp farming, especially in the subtropical regions of Guangdong province in China where the climate is humid and the temperature is high throughout the year [25,26]. In commercial situations, feedstuffs or diets are often stored in paper bags, making the lipids readily susceptible to oxidation. Some studies have shown that oxidative damage in aquatic animals caused by oxidative lipids can be prevented by exogenous antioxidants, such as the supplementation of vitamin E or $\alpha$-tocopherol $[21,24,27]$. In this study, the potential benefits and protective effect of dietary AX in L. vannamei were evaluated in shrimps fed with oxidized fish oil (OFO) for a 50-day period. The chronic effects of dietary OFO and the role of dietary $\mathrm{AX}$, as a possible chemoprotective agent against $\mathrm{OFO}$, were observed. The objectives of this study were (1) to evaluate the chronic effects of dietary OFO on growth performance and hepatopancreas damage of L.vannamei and (2) to determine the benefits of dietary AX in preventing or ameliorating the effect of dietary OFO.

\section{Results}

\subsection{Growth Performance and Feed Utilization}

The growth performance and survival of shrimp are shown in Table 1. After the 50-day feeding trial, the final body weight (FBW) of shrimps fed with the OFO + AX450 diet was significantly higher than those fed with the OFO diet $(p<0.05)$. However, no significant difference was observed between shrimps fed with the OFO + AX450 diet and the control fresh fish oil diet $(p>0.05)$. Lowest weight 
gain (WG), specific growth rate (SGR), and survival rate were found in shrimps fed with the OFO diet, although no significant differences were found in WG, SGR, and survival among other dietary groups $(p>0.05)$. Similarly, a higher feed conversion ratio (FCR) was found in shrimps fed with the OFO + AX150 diet than those fed with the OFO diet and no significant differences were found among other dietary groups $(p>0.05)$.

Table 1. Growth performance and feed utilization of the juvenile L. vannamei, fed with different diets over the 50-day feeding trial.

\begin{tabular}{cccccc}
\hline \multirow{2}{*}{ Items } & D1 & D2 & D3 & D4 & D5 \\
\cline { 2 - 6 } & Control & OFO & OFO + AX150 & OFO + AX250 & OFO + AX450 \\
\hline Initial body & $0.53 \pm 0.02$ & $0.53 \pm 0.01$ & $0.53 \pm 0.01$ & $0.53 \pm 0.02$ & $0.53 \pm 0.01$ \\
weight (g) & & & & \\
Final body & $9.62 \pm 1.42^{\mathrm{a}, \mathrm{b}}$ & $8.31 \pm 0.33^{\mathrm{a}}$ & $8.78 \pm 0.23^{\mathrm{a}, \mathrm{b}}$ & $10.46 \pm 1.77^{\mathrm{a}, \mathrm{b}}$ & $11.09 \pm 2.13^{\mathrm{b}}$ \\
weight (g) & & & & \\
Weight gain (\%) & $1674.2 \pm 106.8^{\mathrm{a}, \mathrm{b}}$ & $1457.7 \pm 62.2^{\mathrm{a}}$ & $1548.7 \pm 24.2^{\mathrm{a}, \mathrm{b}}$ & $1866.7 \pm 335.9 \mathrm{a}, \mathrm{b}$ & $1980.8 \pm 399.9^{\mathrm{b}}$ \\
SGR (\% day $\left.{ }^{-1}\right)$ & $5.13 \pm 0.10$ & $4.90 \pm 0.04$ & $5.00 \pm 0.03$ & $5.30 \pm 0.17$ & $5.40 \pm 021$ \\
Survival (\%) & $87.78 \pm 7.78$ & $75.83 \pm 6.85$ & $81.11 \pm 6.76$ & $88.89 \pm 9.50$ & $86.67 \pm 8.39$ \\
FCR & $1.37 \pm 0.07$ & $1.42 \pm 0.13$ & $1.48 \pm 0.02$ & $1.18 \pm 0.12$ & $1.21 \pm 0.26$ \\
\hline a,b
\end{tabular}

$\mathrm{a}, \mathrm{b}$ Mean values within a row without a common superscript letter were significantly different $(p \leq 0.05)$. Data represent mean \pm SEM of four replicates.

\subsection{Shell Astaxanthin Concentration}

The effect of experimental diets on AX concentration in the shell of shrimps (\% dry weight basis) is presented in Figure 1. We observed an increasing AX content in the shell when we increased the level of dietary AX. Shrimps fed with the OFO diet showed a significantly lower AX level in its shell when compared to those getting the OFO + AX250 and OFO + AX450 diets $(p<0.05)$. We observed no significant difference between shrimps fed with the control fresh fish oil and OFO + AX150 diets $(p>0.05)$.

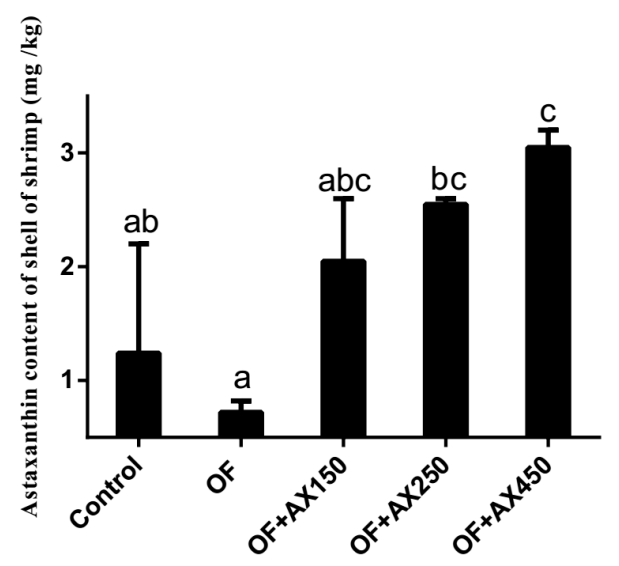

Figure 1. The astaxanthin content of L. vannamei shell fed with different diets over the feeding trial.

\subsection{Survival Rate of Shrimp after the Acute Salinity Change Test}

The survival rates of shrimps after the acute salinity change test for 5 hours in all dietary groups are presented in Figure 2. The lowest survival rate was found in shrimps fed with the OFO diet and was significantly lower than those fed with the OFO + AX450 diet $(p<0.05)$. No significant differences were observed in shrimps fed with the control fresh fish oil, OFO + AX150, and OFO + AX250 diets $(p>0.05)$. 


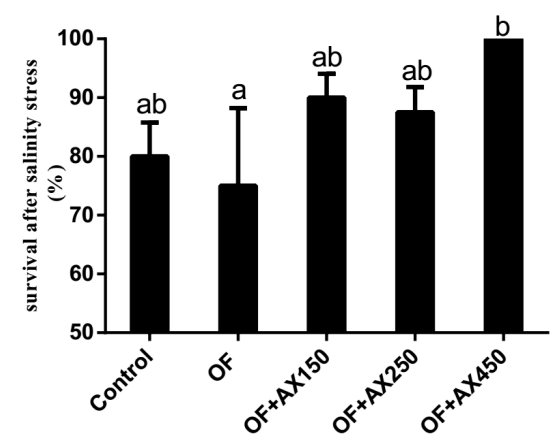

Figure 2. Survival rate (\%) of L.vannamei fed control diet and expermient diets after acute salinity changes for $5 \mathrm{~h}$.

\subsection{Hepatopancreatic and Hemolymph Immune Parameters}

The hemolymph and hepatopancreas immune parameters of shrimps are shown in Table 2. High hepatopancreatic and hemolymph malondialdehyde (MDA) contents in shrimp were induced by the OFO diet, thus, its hemolymph MDA content was significantly higher than in the control group $(p<0.05)$. The lowest catalase (CAT) activity of hemolymph was found in shrimps fed with the OFO diet and that CAT activity showed an increasing pattern along with the increasing dietary AX.

Table 2. Several hemolymph and hepatopancreas parameters of the juvenile L. vannamei fed with different diets.

\begin{tabular}{|c|c|c|c|c|c|}
\hline \multirow{2}{*}{ Items } & D1 & D2 & D3 & D4 & D5 \\
\hline & Control & $\begin{array}{l}\text { Oxidized Fish } \\
\text { Oil (OFO) }\end{array}$ & $\mathrm{OFO}+\mathrm{AX150}$ & $\mathrm{OFO}+\mathrm{AX} 250$ & $\mathrm{OFO}+\mathrm{AX} 450$ \\
\hline $\begin{array}{c}\text { Hemolymph } \\
\text { malondialdehyde (MDA) } \\
\left(\mathrm{mmol} \mathrm{L}^{-1}\right)\end{array}$ & $4.40 \pm 0.40^{\mathrm{a}}$ & $6.76 \pm 0.75^{b}$ & $4.78 \pm 0.29^{a, b}$ & $5.22 \pm 0.22^{a, b}$ & $6.01 \pm 0.36^{\mathrm{a}, \mathrm{b}}$ \\
\hline $\begin{array}{c}\text { Hemolymph catalase } \\
\text { (CAT) } \\
\left(\mathrm{U} \mathrm{L}^{-1}\right)\end{array}$ & $1.07 \pm 0.06^{b, c}$ & $0.54 \pm 0.26^{\mathrm{a}}$ & $0.90 \pm 0.19^{\mathrm{a}, \mathrm{b}}$ & $1.17 \pm 0.14^{\mathrm{b}, \mathrm{c}}$ & $1.50 \pm 0.13^{c}$ \\
\hline $\begin{array}{l}\text { Hepatopancreas MDA } \\
\text { (nmol mg } \mathrm{mg}^{-1} \text { prot ) }\end{array}$ & $1.96 \pm 0.50$ & $3.32 \pm 1.10$ & $3.06 \pm 0.81$ & $2.11 \pm 0.15$ & $1.97 \pm 0.12$ \\
\hline $\begin{array}{c}\text { Hepatopancreas iNOS } \\
\text { (U mg }{ }^{-1} \text { prot) }\end{array}$ & $1.35 \pm 0.11^{\mathrm{a}, \mathrm{b}}$ & $1.28 \pm 0.09^{a}$ & $1.39 \pm 0.10^{\mathrm{a}, \mathrm{b}}$ & $1.54 \pm 0.15^{\mathrm{a}, \mathrm{b}}$ & $1.62 \pm 0.10^{b}$ \\
\hline
\end{tabular}

a,b,c Mean values within a row without a common superscript letter were significantly different $(p \leq 0.05)$. Data represent mean \pm SEM of four replicates.

\subsection{Muscle Fatty Acids Composition}

The muscle fatty acids composition of shrimps are presented in Table 3. Unsaturated fatty acid content (monounsaturated and polyunsaturated fatty acids) in the muscle of shrimps fed with the OFO diet was significantly lower than those fed with the OFO + AX250 diet $(p<0.05)$. In shrimps fed with the OFO diet, the levels of eicosapentaenoic acid (EPA), docosahexaenoic acid (DHA), and omega-3 $(n-3)$ polyunsaturated fatty acids (PUFA) were the lowest, while $n-6$ PUFA was the highest. 
Table 3. Fatty acid composition of muscle from the juvenile L. vannamei (weight \%).

\begin{tabular}{|c|c|c|c|c|c|}
\hline Metabolite $^{\text {a. }}$ & D1 & D2 & D3 & D4 & D5 \\
\hline $14: 0$ & $0.17 \pm 0.03$ & $0.33 \pm 0.14$ & $0.23 \pm 0.04$ & $0.19 \pm 0.05$ & $0.19 \pm 0.04$ \\
\hline $15: 0$ & $0.18 \pm 0.02$ & $0.19 \pm 0.01$ & $0.20 \pm 0.00$ & $0.17 \pm 0.02$ & $0.18 \pm 0.01$ \\
\hline $16: 0$ & $16.83 \pm 1.23$ & $18.60 \pm 1.90$ & $18.27 \pm 0.55$ & $15.10 \pm 1.5$ & $16.03 \pm 1.09$ \\
\hline $16: 1$ & $1.05 \pm 0.15$ & $1.86 \pm 0.66$ & $0.98 \pm 0.17$ & $1.06 \pm 0.28$ & $0.80 \pm 0.11$ \\
\hline $17: 0$ & $0.94 \pm 0.02$ & $0.93 \pm 0.02$ & $0.95 \pm 0.02$ & $0.90 \pm 0.01$ & $0.95 \pm 0.02$ \\
\hline $17: 1$ & $0.71 \pm 0.21$ & $0.45 \pm 0.15$ & $0.75 \pm 0.09$ & $0.87 \pm 0.23$ & $0.68 \pm 0.11$ \\
\hline 18:0 & $12.07 \pm 0.47$ & $11.20 \pm 0.79$ & $12.00 \pm 0.38$ & $12.17 \pm 0.39$ & $12.63 \pm 0.34$ \\
\hline $18: 1$ & $20.27 \pm 0.78$ & $20.30 \pm 0.90$ & $20.63 \pm 0.59$ & $19.67 \pm 1.60$ & $20.03 \pm 0.87$ \\
\hline $18: 2 n-6$ & $10.80 \pm 0.78$ & $11.23 \pm 0.62$ & $10.97 \pm 0.28$ & $10.50 \pm 0.46$ & $10.25 \pm 0.46$ \\
\hline $18: 3 n-3$ & $0.58 \pm 0.03$ & $0.59 \pm 0.03$ & $0.55 \pm 0.06$ & $0.52 \pm 0.02$ & $0.54 \pm 0.01$ \\
\hline $20: 0$ & $0.22 \pm 0.03$ & $0.18 \pm 0.06$ & $0.25 \pm 0.04$ & $0.18 \pm 0.09$ & $0.27 \pm 0.12$ \\
\hline $20: 1$ & $1.04 \pm 0.08$ & $0.98 \pm 0.12$ & $0.96 \pm 0.04$ & $1.06 \pm 0.04$ & $1.10 \pm 0.00$ \\
\hline C20:2 & $1.77 \pm 0.17$ & $1.47 \pm 0.31$ & $1.77 \pm 0.09$ & $1.97 \pm 0.12$ & $1.98 \pm 0.08$ \\
\hline C22:0 & $0.30 \pm 0.02$ & $0.33 \pm 0.04$ & $0.30 \pm 0.02$ & $0.25 \pm 0.13$ & $0.33 \pm 0.03$ \\
\hline C 20:4n-6 & $3.03 \pm 0.30$ & $2.68 \pm 0.54$ & $3.13 \pm 0.12$ & $3.70 \pm 0.40$ & $3.33 \pm 0.19$ \\
\hline C 20:5n-3 & $12.97 \pm 1.03$ & $9.98 \pm 0.79$ & $12.00 \pm 0.38$ & $12.17 \pm 0.39$ & $12.63 \pm 0.34$ \\
\hline C24:0 & $0.37 \pm 0.04^{\mathrm{a}, \mathrm{b}}$ & $0.26 \pm 0.01^{a}$ & $0.40 \pm 0.05^{\mathrm{a}, \mathrm{b}}$ & $0.54 \pm 0.07^{b}$ & $0.45 \pm 0.07^{\mathrm{a}, \mathrm{b}}$ \\
\hline C24:1 & $0.66 \pm 0.33$ & $0.37 \pm 0.22$ & $0.49 \pm 0.19$ & $0.95 \pm 0.53$ & $0.85 \pm 0.36$ \\
\hline C 22:5 n-6 (EPA) & $1.63 \pm 0.12$ & $1.18 \pm 0.40$ & $1.17 \pm 0.12$ & $1.53 \pm 0.32$ & $1.65 \pm 0.14$ \\
\hline C 22:6 n-3 (DHA) & $14.27 \pm 0.64$ & $13.47 \pm 0.75$ & $13.47 \pm 0.87$ & $14.17 \pm 0.69$ & $14.80 \pm 0.83$ \\
\hline $\mathrm{EPA}+\mathrm{DHA}$ & $27.23 \pm 1.55$ & $25.73 \pm 1.94$ & $25.80 \pm 1.20$ & $28.73 \pm 2.36$ & $28.18 \pm 1.55$ \\
\hline DHA/EPA & $1.11 \pm 0.06$ & $1.10 \pm 0.03$ & $1.09 \pm 0.04$ & $0.99 \pm 0.07$ & $1.11 \pm 0.03$ \\
\hline SAFA $^{1}$ & $31.10 \pm 0.85$ & $31.72 \pm 0.94$ & $32.60 \pm 0.90$ & $29.44 \pm 0.90$ & $31.00 \pm 1.16$ \\
\hline UFA $^{2}$ & $68.76 \pm 0.87^{\mathrm{a}, \mathrm{b}}$ & $66.11 \pm 2.08^{a}$ & $66.88 \pm 1.20^{\mathrm{a}, \mathrm{b}}$ & $70.56 \pm 0.89^{b}$ & $68.92 \pm 1.16^{\mathrm{a}, \mathrm{b}}$ \\
\hline$n-3$ PUFA $^{3}$ & $29.44 \pm 1.56$ & $22.69 \pm 5.37$ & $27.52 \pm 1.16$ & $30.79 \pm 2.62$ & $30.37 \pm 1.63$ \\
\hline$n-6$ PUFA & $13.83 \pm 0.49$ & $15.08 \pm 0.73$ & $14.10 \pm 0.29$ & $14.20 \pm 0.17$ & $13.58 \pm 0.39$ \\
\hline$n-3 / n-6$ ratio & $2.14 \pm 0.18$ & $1.56 \pm 0.41$ & $1.95 \pm 0.05$ & $2.17 \pm 0.20$ & $2.24 \pm 0.14$ \\
\hline
\end{tabular}

a,b Mean values within a row without a common superscript letter were significantly different $(p \leq 0.05) .{ }^{1}$ SAFA: saturated fatty acid; ${ }^{2}$ UFA: unsaturated fatty acid; ${ }^{3}$ PUFA: poly unsaturated fatty acid.

\subsection{Hepatopancreas Histology}

We observed lesions in the hepatopancreas of shrimps fed with the OFO diet. The tubular epithelial cells of the hepatopancreas were heavily vacuolated and some were ruptured. Melanization of the epithelial cells and significant reduction of B-cells were evident (Figure 3b). Dietary AX supplementation markedly attenuated the hepatopancreatic tissue injury induced by the oxidized fish oil, so that a similar or even better histopathological picture was observed in comparison to the control group (Figure 3a). Furthermore, increased distance between adjacent tubules and abnormal lumen of the tubules was observed in the control group (Figure 3a). AX co-treatment stored the normal electron microscopic appearance of hepatopancreas, making similar or even better histology than that observed in the control group (Figure $3 \mathrm{c}-\mathrm{e}$ ) 
a

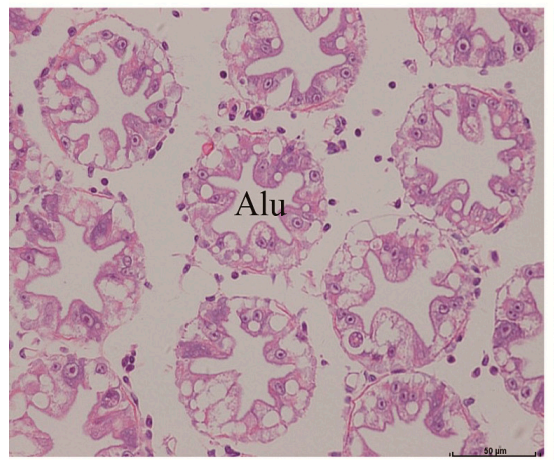

d

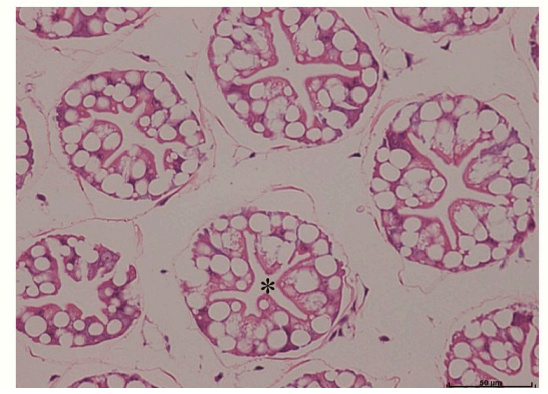

b

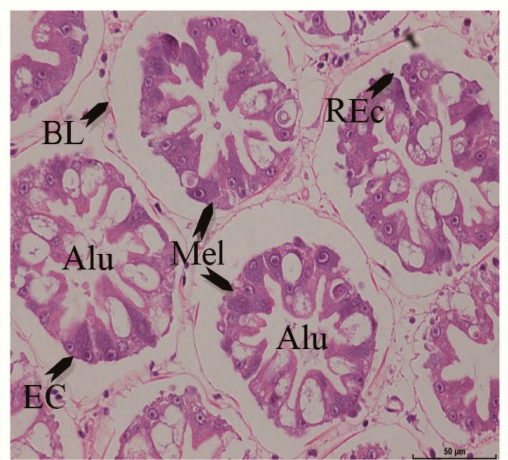

C

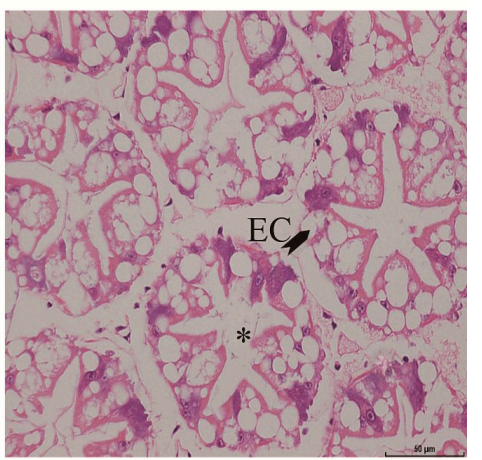

e

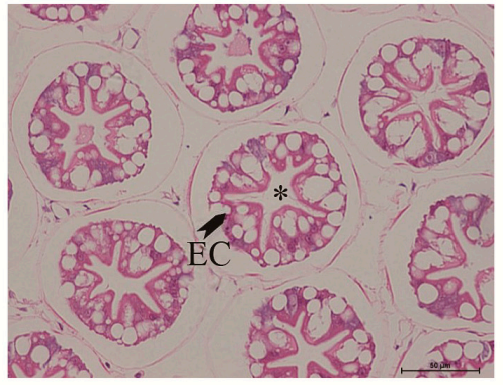

Figure 3. Hepatopancreas from experiment diets treated L. vannamei. (a) The hepatopancreas from a shrimp fed with contol diet for $50 \mathrm{~d}$. Bar $=50 \mu \mathrm{m}$. Tubular epithelial cells have detached from the basal lamina with this treatment, and the tubules have atrophied, the tubular epithelial cells are slightly vacuolated. (b) The hepatopancreas from a shrimp fed with oxidized fish oil diet for $50 \mathrm{~d}$. Bar $=50 \mu \mathrm{m}$. The hepatopancreas from a shrimp showing that the tubular epithelial cells are heavily vacuolated; and some are ruptured. Melanization of the epithelial cells has appeared. (c) The hepatopancreas from a shrimp fed with oxidized fish oil + AX $150 \mathrm{mg} / \mathrm{kg}$ diet for $50 \mathrm{~d}$. Bar $=50 \mu \mathrm{m}$. Transverse section of the middle proximal region of tubules showing that tubules are well arranged and appear as a star shape in the lumen. Different cell types can be observed, and the quantity of these cells are more than the control and OFO groups. (d) The hepatopancreas from a shrimp fed with oxidized fish oil + AX $250 \mathrm{mg} / \mathrm{kg}$ diet for $50 \mathrm{~d}$. Bar $=50 \mu \mathrm{m}$. (e) The hepatopancreas from a shrimp fed with oxidized fish oil + AX $450 \mathrm{mg} / \mathrm{kg}$ diet diet for $50 \mathrm{~d}$. Bar $=50 \mu \mathrm{m}$. Both (e) and (f) show that tubules are normally appearing as a star shape in the lumen. Different cell types can also be observed. ALU, abnormal lumen; BL, basal lamina; REc, ruptured epithelial cells; Mel, melanization of cells; ${ }^{*}$, star shape of the lumenof cells; ${ }^{*}$, star shape of the lumen.

TEM analysis demonstrated that in the hepatopancreas from shrimp fed with OFO and OFO/AX450 diet for $50 \mathrm{~d}$, the rough endoplasmic reticulum in many B cells undergoes a marked swelling and vesiculation and have showed large vacuoles, the internal cristae of mitochondria decreased, the cristae disappeared in severe cases, and the RER structure was fuzzy (Figure 4a,b). Dietary OFO/AX450 supplementation attenuated the hepatopancreatic injury induced by OFO (Figure 4c,d). 

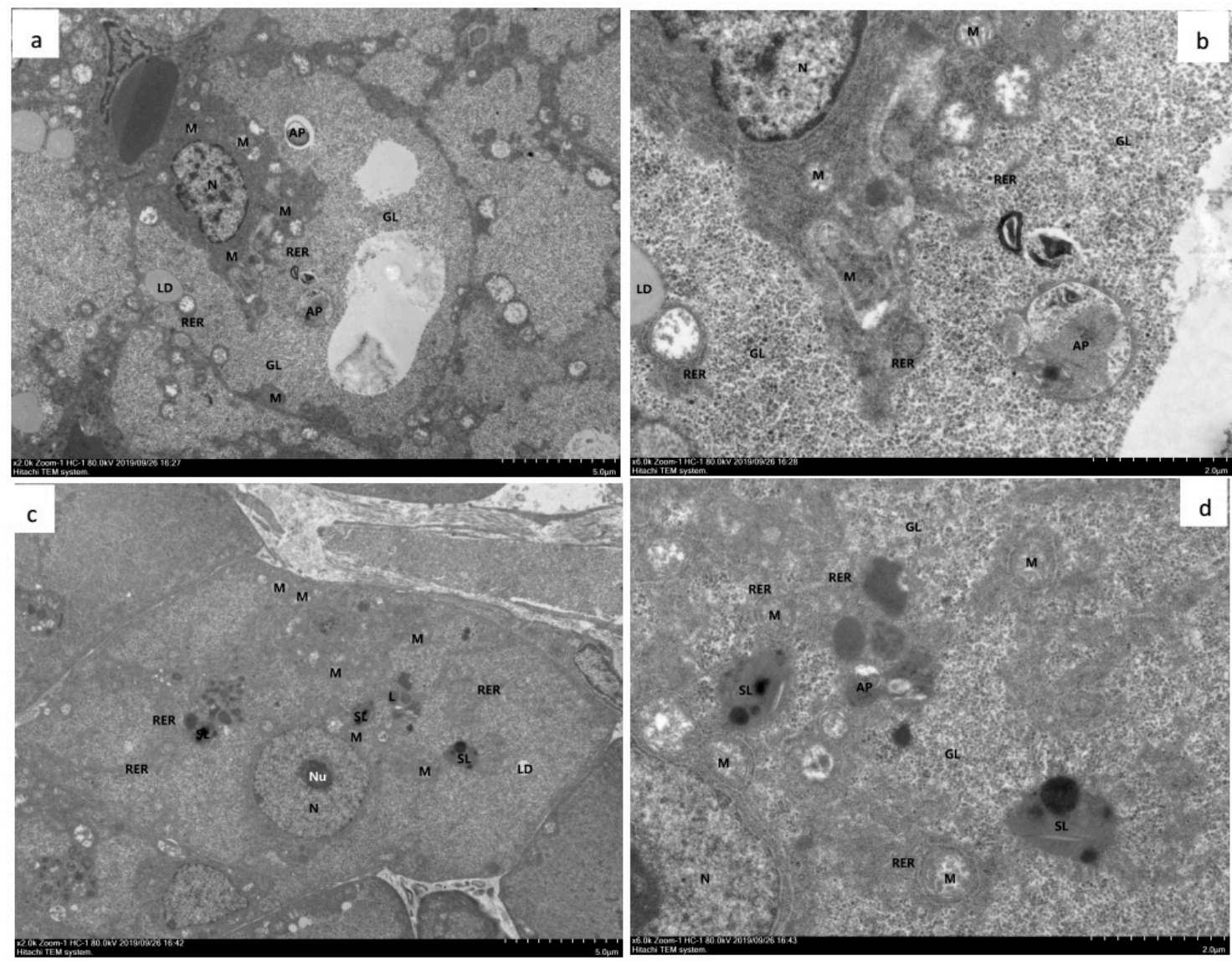

Figure 4. Hepatopancreas from experimental diets treated with Litopenaeus vannamei. a-d TEM (a) and (b). The hepatopancreas from shrimp fed with OFO diet for $50 \mathrm{~d}$. The hepatocytes showed moderate edema, intact cell membrane, moderate swelling and vacuolation of organelles in the cytoplasm, more vacuoles in the cells, and local electron density decreased. The mitochondria (M) showed slight swelling, most of the mitochondrial matrix slightly weakened, the internal cristae decreased, and the cristae disappeared in severe cases; the RER structure was fuzzy. Glycogen (GL) was abundant. Autophagy (AP) was abundant. Lipid droplets (LD) are present individually. There are more lysosomes (L) and secondary lysosomes (SL). (c) and (d) The hepatopancreas from shrimp fed with OFO/AX450 diet for $56 \mathrm{~d}$. The liver cells showed mild edema, intact cell membrane, slight swelling of intracellular organelles, and a few vacuolations. autophagy (AP), mitochondria (M), large vacuoles (V), nucleoli $(\mathrm{Nu})$, nucleus $(\mathrm{N})$, Glycogen (GL), lysosomes (L), secondary lysosomes (SL), rough endoplasmic reticulum (RER).

\section{Disscussion}

The present study investigated whether AX supplements confer protection against the chronic effects of the OFO diet on the growth performance and hepatotoxicity in Pacific white shrimps. Dietary OFO has been related to reduced nutrient digestibility [28] and low nutritional value of feed materials, by destroying the PUFA contents and other essential food constituents [29]. It has been shown in several studies that feeding oxidized lipids did not lead to any reduction in the growth of several different fish species $[12,30,31]$. On the contrary, a reduction in growth caused by OFO was also observed in some aquatic animals, including Labeo rohita fingerlings [32], Pagrus major [33] and M. salmoide [34]. Yang et al. (2015) demonstrated a significant reduction of growth in juvenile L. vannamei fed with the OFO diet (peroxide value (POV): $234.84 \mathrm{meq} / \mathrm{kg}$ ) [35]. The reduced weight gains of the animals fed with the dietary oxidized lipid may be due to altered palatability, leading to poor growth performance [21,24,27].

Dietary AX, as a powerful antioxidant, could enhance nutrient utilization and ultimately improve growth. Aside from that, AX could increase stress tolerance and play an important role in the 
intermediary metabolism of aquatic animals [36-38]. In this study, adequate AX supplements in the OFO diet substantially improve the growth performance of $L$. vannamei. AX has the same function as Vitamin E [39] and Selenium (Se) [40] in protecting lipid oxidation, thereby maximizing nutrient availability in the diet of L. vannamei [6,10].

The thiobarbituric acid reactive substances (TBARS) test is widely used as a single assay for measuring lipid peroxidation by-product MDA. In this study, we show that the MDA level in the hemolymph increases significantly in shrimps fed with the OFO diet, suggesting that OFO induces a state of oxidative stress. Dietary AX abrogates the degree of lipid peroxidation, as the MDA level decreases in the hemolymphs of shrimps when AX is incorporated into the OFO diet. Similar to our study, other researchers documented that the TBARS level was increased in serum and liver due to dietary oil oxidation $[21,24,27]$. CAT is one of the major antioxidant enzymes responsible for scavenging reactive oxygen species (ROS) and serves as a protective mechanism to avoid tissue damage caused by free-radicals and phagocytosis [5]. We show that CAT activity in the hemolymph of shrimp fed with the OFO diet decreases significantly. This result indicates that, under the OFO diet, the capacity of shrimp to scavenge free radicals reduces dramatically. As a powerful biological antioxidant, the moderate concentration of AX in the diet could inhibit MDA accumulation and thus the observed decline in CAT activity. Previous studies demonstrated that AX had strong $\mathrm{O}^{2}$ quenching activity and dietary AX could relieve oxidative stress [6,10]. Our results suggest that dietary AX could partially alleviate oxidative stress caused by the OFO diet in L. vannamei, which could help to reduce damage caused by reactive oxygen species.

Previous studies indicated that dietary AX could enhance stress tolerance in aquatic animals. Pan et al. (2003) and Chien and Shiau (2005) showed that P. monodon fed with AX diets had an increased survival rate after the thermal, osmotic, ammonia, and low dissolved oxygen (DO) challenges [41,42]. Chien and Shiau (2005) suggested that under low DO conditions, M. Japonicus fed with algae or synthetic AX diets had longer survival time than the control group [41]. In the acute salinity change test, we show that shrimps fed with the OFO diet have a lower survival rate compared with the control group, while those fed with AX supplements have a higher survival rate compared with the OFO group. These results indicate that AX supplementation could ameliorate the low resistance capacity to salinity stress in shrimps fed OFO.

It is well known that OFO could induce pathological changes in the hepatopancreas of terrestrial and aquatic organisms. Chen et al. (2012) suggested an increased oxidative stress in M. salmoides fed with an oxidized lipid may account for the observed pathological changes [43]. The hepatopancreas is an important digestive organ that possesses several functions, including absorption, digestion, storage, secretion, and detoxification in crustaceans $[44,45]$. The hepatopancreas is essentially composed of branched tubules and different types of epithelial cells lining the tubules. The hepatopancreas of a crustacean is sensitive to diet-born pollutants and is often used to monitor the effect of various toxicants [46]. In this study, histological examinations in shrimps under the OFO diet indicate degenerative features in the tubules and epithelial cells of the hepatopancreas, but the addition of dietary AX attenuates these histopathological changes (Figure 3). From the TEM analysis, we found that rough endoplasmic reticulum in the B cells underwent a marked swelling and vesiculation. These results suggest that shrimps could benefit from dietary AX by ameliorating any pathological changes associated with oxidized lipids.

The diets containing oxidized lipids might be considered deficient in essential fatty acids according to the National Research Council (2011) [47]. In the present study, fatty acid profiles in the muscle and AX in the shell were altered under dietary OFO and AX supplementation. The UFA of the muscle got the highest value in the OFO + AX250 diet treatment and was significantly higher than that in the OFO diet treatment. The present AX content was reduced from $1.24 \mathrm{mg} / \mathrm{kg}$ in the control diet treatment to $0.72 \mathrm{mg} / \mathrm{kg}$ in the OFO diet treatment, which may indicate that shrimps consuming AX supplements could resist oxidative stress. Correlation analysis showed that hepatopancreas MDA did not only have a highly significant positive correlation with UFA, but also had a significant negative correlation 
with survival rates over the feeding trial or after an acute salinity change test. This may suggest that mortality and stress tolerance were related to lipid peroxidation in hepatopancreas. Survival rates after the acute salinity change test had a significant positive correlation with AX content of shell, which indicates a direct or indirect relationship between $A X$ and stress tolerance. The concentration of $A X$ stored in shrimp was increased with an increasing level of dietary AX. Moreover, AX could reduce tissue lipid peroxidation and the decreased lipid peroxidation products may serve to protect muscle UFA content from the detrimental effects of oxidation. Consequently, the present research hypothesizes that AX might play an important role in the detoxification of peroxidation caused by dietary oxidized fish oil.

\section{Materials and Methods}

\subsection{Diet Preparation}

Juvenile L. vannamei were fed with five isonitrogenous and isolipidic diets. Diets were formulated with different levels of dietary oxidized fish oil and/or with astaxanthin (AX) (Lucantin ${ }^{\circledR}$ Pink $10 \%$; BASF SE, Ludwigshafen, Germany) supplements. The dietary conditions were as follows: (i) OFO (oxidized fish oil); (ii) OFO/AX150 (oxidized fish oil + AX150 mg/kg); (iii) OFO/AX250 (oxidized fish oil + AX250 mg/kg); (iv) OFO/AX450 (oxidized fish oil + AX450 mg/kg); and, (v) control group (fresh fish oil) (Table 4). The peroxide value of oxidized fish oil was $275.2 \mathrm{meq} / \mathrm{kg}$. Each diet was fed to a quadruplicate group of shrimp. Briefly, all the powdery ingredients were accurately weighed, thoroughly blended, and then lipids and water were added. Cold-extruded pellets (1.2 mm in diameter) were air-dried to approximately $10 \%$ moisture. The dried pellets were placed in the vacuum-packed bags and stored at $-20{ }^{\circ} \mathrm{C}$ until used. A total of $40 \mathrm{~g}$ of each diet was sampled for biochemical composition analysis [48].

Table 4. Composition and nutrient levels of experimental diets.

\begin{tabular}{|c|c|c|c|c|c|}
\hline \multirow{2}{*}{ Items } & D1 & D2 & D3 & D4 & D5 \\
\hline & Control & OFO & OFO + AX150 & $\mathrm{OFO}+\mathrm{AX} 250$ & $\mathrm{OFO}+\mathrm{AX} 450$ \\
\hline \multicolumn{6}{|c|}{ Ingredients ( $\mathrm{g} \mathrm{kg}^{-1}$ diet) } \\
\hline Fish meal & 220 & 220 & 220 & 220 & 220 \\
\hline Soybean meal & 210 & 210 & 210 & 210 & 210 \\
\hline Wheat flour & 245 & 245 & 245 & 245 & 245 \\
\hline Peanut meal & 100 & 100 & 100 & 100 & 100 \\
\hline soybean protein concentrate & 60 & 60 & 60 & 60 & 60 \\
\hline Beer yeast & 50 & 50 & 50 & 50 & 50 \\
\hline Chicken meal & 30 & 30 & 30 & 30 & 30 \\
\hline Fresh Fish oil & 30 & 0 & 0 & 0 & 0 \\
\hline Oxidized fish oil & 0 & 30 & 30 & 30 & 30 \\
\hline Soya lecithin & 10 & 10 & 10 & 10 & 10 \\
\hline Vitamin premix ${ }^{a}$ & 10 & 10 & 10 & 10 & 10 \\
\hline Mineral premix $\mathrm{b}$ & 10 & 10 & 10 & 10 & 10 \\
\hline $\mathrm{Ca}\left(\mathrm{H}_{2} \mathrm{PO}_{4}\right)_{2}-\mathrm{H}_{2} \mathrm{O}$ & 20 & 20 & 20 & 20 & 20 \\
\hline
\end{tabular}


Table 4. Cont.

\begin{tabular}{|c|c|c|c|c|c|}
\hline \multirow{2}{*}{ Items } & D1 & D2 & D3 & D4 & D5 \\
\hline & Control & OFO & OFO + AX150 & $\mathrm{OFO}+\mathrm{AX} 250$ & $\mathrm{OFO}+\mathrm{AX} 450$ \\
\hline Vitamin C & 1 & 1 & 1 & 1 & 1 \\
\hline Choline chloride (50\%) & 2 & 2 & 2 & 2 & 2 \\
\hline Astaxanthin (10\%) & 0 & 0 & 0.15 & 0.25 & 0.45 \\
\hline Cellulose & 2 & 2 & 1.85 & 1.75 & 1.55 \\
\hline \multicolumn{6}{|c|}{ Proximate analysis $\left(\mathrm{g} \mathrm{kg}^{-1}\right.$ diet $)$} \\
\hline Crude protein & 390.1 & 391.1 & 392.6 & 392.6 & 393.1 \\
\hline Crude lipid & 71 & 70 & 71 & 71 & 74 \\
\hline Astaxanthin (mg/kg) & 0.47 & 0 & 57 & 170 & 289 \\
\hline \multicolumn{6}{|c|}{$\begin{array}{l}\text { a Vitamin mixture }\left(\mathrm{mg} \text { or g kg }{ }^{-1}\right) \text { : vitamin } \mathrm{A}, 250,000 \mathrm{IU} ; \text { riboflavin, } 750 \mathrm{mg} \text {; pyridoxine } \mathrm{HCL}, 400 \mathrm{mg} \text {; cyanocobalamin, } \\
1 \mathrm{mg} \text {; thiamin, } 250 \mathrm{mg} \text {; menadione, } 250 \mathrm{mg} \text {; folic acid, } 125 \mathrm{mg} \text {; biotin, } 10 \mathrm{mg} \text {; } \alpha \text {-tocopherol, } 2.5 \mathrm{~g} \text {; myo-inositol, } \\
8000 \mathrm{mg} \text {; calcium pantothenate, } 1250 \mathrm{mg} \text {; nicotinic acid, } 2000 \mathrm{mg} \text {; choline chloride, } 8000 \mathrm{mg} \text {; vitamin } \mathrm{D} 3,45,000 \\
\mathrm{IU} \text {; vitamin C, } 7000 \mathrm{mg} \text {. b Mineral mix }\left(\mathrm{g} \mathrm{kg}^{-1}\right): \mathrm{ZnSO}_{4} \cdot 7 \mathrm{H}_{2} \mathrm{O}, 0.04 \mathrm{~g} ; \mathrm{CaCO}_{3}, 37.9 \mathrm{~g} ; \mathrm{KCl}, 5.3 \mathrm{~g} ; \mathrm{KI}_{1} 0.04 \mathrm{~g} ; \mathrm{NaCl} \text {, } \\
2.6 \mathrm{~g} ; \mathrm{CuSO}_{4} \cdot 5 \mathrm{H}_{2} \mathrm{O}, 0.02 \mathrm{~g} ; \mathrm{CoSO}_{4} \cdot 7 \mathrm{H}_{2} \mathrm{O}, 0.02 \mathrm{~g} ; \mathrm{FeSO}_{4} \cdot 7 \mathrm{H}_{2} \mathrm{O}, 0.9 \mathrm{~g} ; \mathrm{MnSO}_{4} \cdot \mathrm{H}_{2} \mathrm{O}, 0.03 \mathrm{~g} ; \mathrm{MgSO}_{4} \cdot 7 \mathrm{H}_{2} \mathrm{O}, 3.5 \mathrm{~g} \text {; } \\
\mathrm{Ca}\left(\mathrm{HPO}_{4}\right) 2 \cdot 2 \mathrm{H}_{2} \mathrm{O}, 9.8 \mathrm{~g} \text {. }\end{array}$} \\
\hline
\end{tabular}

The oxidized fish oil was prepared as follows: (1) fish oil was oxidized by heating at $70{ }^{\circ} \mathrm{C}$ under vigorous aeration; (2) After $36 \mathrm{~h}$, peroxide value (POV) was monitored every $8 \mathrm{~h}$ intervals until high oxidation level $(275.2 \mathrm{meq} / \mathrm{kg})$ was reached. Peroxide values were determined according to AOAC. Briefly, $5 \mathrm{~g}$ oil, $0.5 \mathrm{~mL}$ saturated $\mathrm{KI}$ solution and $30 \mathrm{~mL}$ solvent mixture comprising of acetic acid and chloroform (3:2) were combined. Titration was carried against $0.1 \mathrm{~mol} / \mathrm{L} \mathrm{Na} 2 \mathrm{~S} 2 \mathrm{O} 3$, using $1 \%$ starch indicator. In the same way, we repeated this with the reagent blank test. Then, we calculated and analysed the measurement results. Calculation: $X=[(V-V 0) \times N \times 0.1269] / \mathrm{m}(X:$ Peroxide value of the sample, $\%$. $V$ : Volume of sodium thiosulfate solution consumed by the sample, $\mathrm{mL}$. $V 0$ : The volume of blank consumption of sodium thiosulfate solution, $\mathrm{mL}$. N: The molar concentration of sodium thiosulfate standard solution, $\mathrm{mol} / \mathrm{L}$.) [33].

\subsection{Shrimp and Experimental Conditions}

The stocks of juvenile L. vannamei were supplied by Evergreen South Ocean Tech Co. Ltd, Zhan-jiang, China. Prior to the experiment, shrimps were acclimatized to the new environment by placing them in the tanks for two weeks, feeding with a commercial diet (Guangdong evergreen Group, Zhan-jiang, China), and providing with aerated recirculating filtered seawater. Afterward, shrimps (initial body weight of $0.53 \mathrm{~g}$ ) were distributed randomly into 20 fiberglass tanks ( $300 \mathrm{~L}, 0.6 \mathrm{~m}^{2}$ bottom, 4 tanks per diet, 30 shrimps per tank). All groups were fed four times a day (at 7:00, 12:00, 17:00 and 21:00) by hand, with a total amount of approximately $9 \%$ of its body weight. To maintain a suitable culture condition, all uneaten food and feces were siphoned out throughout the 50-day experiment period.

During the experimental period, temperature ranged from 27 to $30{ }^{\circ} \mathrm{C}$, salinity was approximately $27 \%-30 \%$, pH was 7.7-8.0, ammonia nitrogen was not more than $0.05 \mathrm{mg} / \mathrm{L}$, and dissolved oxygen was not less than $6.5 \mathrm{mg} / \mathrm{L}$.

\subsection{Sample Collection}

All shrimps were fasted for $24 \mathrm{~h}$ before sampling. During sampling, shrimps were weighed individually and collected for further analysis. For each tank, 5 shrimps were collected randomly for shell AX content and muscle fatty acid (FA) analysis, whereas 6 shrimps were collected randomly for hemolymph and hepatopancreas samples. Hemolymph was sampled from the abdominal cavity or around the heart ventricle using a $1 \mathrm{~mL}$ syringe. The hemolymph samples were kept undisturbed in 
the refrigerator for $24 \mathrm{~h}$ at $4{ }^{\circ} \mathrm{C}$ and then centrifuged for $10 \min \left(4^{\circ} \mathrm{C}, 8000 \mathrm{rpm}\right)$. The supernatants were used for the analysis of enzyme activity and malondialdehyde (MDA) content. Six samples of hepatopancreas were immediately placed into liquid nitrogen and stored at $-80^{\circ} \mathrm{C}$. Before the analysis of enzyme activity, the hepatopancreas of each shrimp was weighed $(0.5 \mathrm{~g})$ individually and homogenized in $10 \times(\mathrm{w} / \mathrm{v})$ phosphate buffer solution $\left(0.1 \mathrm{~mol} \mathrm{~L}^{-1}, \mathrm{pH} 6.4\right)$ in ice-water. The homogenate was centrifuged $(6000 \mathrm{rpm}, 10 \mathrm{~min})$ at $4{ }^{\circ} \mathrm{C}$ and an aliquot of the supernatant was used to determine the hepatic MDA.

\subsection{Histopathological Studies}

The sampled hepatopancreas of three shrimps (per tank) were fixed in neutral $4 \%$ formalin and later embedded in paraffin. Tissue sections ( $8 \mu \mathrm{m}$ thickness) of the hepatopancreas were stained with hematoxylin and eosin (H\&E) stain and the final slides were examined under the light microscope for histopathological lesions.

For the TEM microscopy, the specimens were fixed in $2.5 \%$ glutaraldehyde with $0.1 \mathrm{M}$ phosphate-buffer and postfixed in $1 \% \mathrm{OsO}_{4}$. The specimens were emmbedded in Spurr's medium epoxy resin after dehydration in a graded acetone (Polysciences Ltd., Warrington, PA, USA). An ultratome Leica UCT was used for cutting ultrathin sections, and then ultrathin sections were stained with lead citrate and a saturated solution of uranylacetate in $50 \%$ ethanol. Ultrathin sections were then screened with a TEM (FEI Tecnai G2 20, Holland) at $150 \mathrm{kV}$ and the images were acquired by a camera Megaview III (SIS GmbH), equipped with software AnalySIS.

\subsection{Fatty Acid Composition}

Total lipid was extracted using chloroform: methanol (2:1, v/v). The capillary gas chromatography (GC) method was employed to determine the fatty acid profile. The HP6890 (FID detector; Agilent Technologies, Palo Alto, CA, USA) and SPTM-2380 column $(30 \mathrm{~m} \times 0.25 \mathrm{~mm} \times 0.20 \mu \mathrm{m})$ were used on the GC machine. The separation was carried out with nitrogen as the carrier gas. Temperature of the column increased from 140 to $240{ }^{\circ} \mathrm{C}$ at $4{ }^{\circ} \mathrm{C} \mathrm{min}-1$, held at $140{ }^{\circ} \mathrm{C}$ for $5 \mathrm{~min}$ and at $240{ }^{\circ} \mathrm{C}$ for $10 \mathrm{~min}$, with a detector at $260^{\circ} \mathrm{C}$. A split injector (50:1) at $260^{\circ} \mathrm{C}$ was used. Each fatty acid was identified by the retention time from the chromatographic standard (Sigma, Northampton, UK). Peak areas were determined using the Varian software (Varian, Inc., Palo Alto, CA, USA). The concentration of the individual fatty acid was expressed in percentage of total fatty acids.

\subsection{Astaxanthin Content of the Shell}

According to the methods of Chien and Shiau (2005) [41], the shells of ten shrimps from each tank were dissected, freeze-dried, minced, and placed into a 50-mL polypropylene centrifuge tube. The solvent acetone $(20 \mathrm{~mL})$ was added into each tube to homogenize the mixture (Polytron PT-MR-3000; PT. Hartono IstanaTeknologi, Indonesia) at $12700 \times g$ for $1 \mathrm{~min}$ and then centrifuged (Hitachi 18 PR-52; Hitachi Ltd., Tokyo, Japan) at $12700 \times g$ for $5 \mathrm{~min}$. The pellet was resuspended and centrifuged with an additional $20 \mathrm{~mL}$ of acetone, until the acetone extract was clear. The pooled acetone extracts were transferred into a 250-mL separatory funnel partitioned with $30 \mathrm{~mL}$-hexane and washed three times with $10 \% \mathrm{NaCl}$ to remove the residual acetone. Then, the extract was reduced to $10 \mathrm{~mL}$ using a rotary evaporator. Afterward, the extract was filtered through a $0.2 \mathrm{Am}$ Millipore filter and stored in three 2-mL brown vials. AX contents were determined using high-performance liquid chromatography (Agilent 1200; Agilent technologies, Waldbronn, Germany). The standard of the chromatographically pure AX was purchased from Sigma-Aldrich Co. LLC (St. Louis, MO, USA). The HPLC condition was adjusted according to the previous method of Yuan et al. (1996) [49]. Chromatographic peaks were identified by comparing retention times against known standards. 


\subsection{Lipid Peroxidation and Enzyme Activity Assays}

Lipid peroxidation (LPO) was assessed by measuring thiobarbituric acid-reactive substances (TBARS) during an acid heating reaction, as previously described of Esterbauer and Cheeseman (1990) [50]. The determination of LPO content in shrimp was carried out using the MDA detection kit (A003-1, Jian-cheng Bioengineering Institute, Nan jing, China). The results were expressed in nmol MDA equivalents per milligram protein of hepatopancreas and mmol MDA equivalents per liter of hemolymph.

Catalase (CAT) activity was determined using a test kit (Jian-cheng Institute of Biotechnology, Nan jing, China). CAT activities of tissue was measured spectrophotometrically at 405 using a SpectraMax M5 microplate reader (Molecular Devices, Minneapolis, MN, USA). One unit of CAT activity was defined as the amount of enzyme that catalyzed the decomposition of $1.0 \mu$ mol of $\mathrm{H}_{2} \mathrm{O}_{2}$ per min. The results were expressed in U/L of hemolymph [48].

iNOS activity was determined using an iNOS assay kit (Jiancheng Bioengineering Institute, Nanjing, China). Briefly, $10 \%$ brain homogenate $(30 \mu \mathrm{L})$ or serum $(15 \mu \mathrm{L})$ was mixed with the working solution supplied in the kit, and after incubation at $37^{\circ} \mathrm{C}$ for $15 \mathrm{~min}$, the reaction was terminated by adding the terminating solution provided in the kit. The absorbance at $530 \mathrm{~nm}$ was recorded on a Hitachi U-2010 spectrophotometer (Tokyo, Japan), and iNOS activity was calculated in the reference of a standard curve. The amount of NO generated in samples was determined by measuring the absorbance at $550 \mathrm{~nm}$.

\subsection{Acute Salinity Change Experiment}

A total of 10 shrimps per tank were randomly selected for the acute salinity change experiment. The test involved an immediate salinity decreasing level from $29 \%$ to $10 \%$ by adding de-chlorinated freshwater. Shrimps were carefully monitored and mortality was recorded during the whole 5-hour-experiment.

\subsection{Calculations and Statistical Analysis}

The parameters were calculated as follows:

$$
\text { Percentage weight gain }(\mathrm{WG}, \%)=100 \times(\mathrm{W} t-\mathrm{Wi}) / \mathrm{Wi}
$$

Specific growth rate $\left(\mathrm{SGR}, \%\right.$ day $\left.^{-1}\right)=100 \times(\operatorname{Ln} W t-\mathrm{Ln} W i) / t$

Feed conversion rate $(\mathrm{FCR})=$ feed consumed $(\mathrm{g}$, dry weight)/weight gain $(\mathrm{g}$, wet weight)

$$
\text { Survival }(\%)=100 \times(\text { final amount of shrimp }) /(\text { initial amount of shrimp })
$$

where $W t$ is the final body weight $(\mathrm{g}), W i$ is the initial body weight $(\mathrm{g})$, and $t$ is the experimental duration in days.

Analyses of all data included the homogeneity test, and if similar variances were observed, a one-way ANOVA was performed to determine the main effect of dietary manipulation. When significant differences $(P \leq 0.05)$ emerged after one-way ANOVA, the group means were compared further using Duncan's multiple range test. On the other hand, if the data did not have similar variances, the non-parametric Kruskal-Wallis test was applied, followed by pairwise multiple comparisons if the results of the Kruskal-Wallis test showed significant difference $(P \leq 0.05)$. Correlation analyses were also used to determine the relationships between biochemical parameters. All data were analyzed using the SPSS 19.0 software (SPSS, Chicago, IL, USA) and the results were presented as the means \pm SEM. 


\section{Conclusions}

Overall, the present work demonstrated that dietary oxidized fish oil (POV: $275.2 \mathrm{meq} / \mathrm{kg}$ ) could cause obvious histopathological changes and oxidative stress in the L. vannamei. Moreover, dietary AX may ameliorate these effects by increasing the CAT activity and decreasing MDA accumulation in the hemolymph of shrimp. Shrimps fed with dietary AX had a better capability to sustain the acute salinity stress tolerance test. More in-depth studies are required to verify the potential mechanism of $\mathrm{AX}$ in alleviating oxidative insult and hepatotoxicity in shrimps and other crustaceans.

Author Contributions: The authors thank the participants who gave their time to the trial. Y.Y., J.N., Y.L. and L.T., designed the study. D.X., gave suggestion for study design. W.Z. and P.Y. gave a hand with the rearing work, W.F., J.X., and M.W. helped to collect the samples. Y.Y., and Y.L., analyzed the results and wrote the paper with contributions from the other authors. All authors have read and agreed to the published version of the manuscript.

Funding: This research was supported by the fund of China Agriculture Research Systerm-47, and Project of Guangdong Natural Science Foundation (2017A030310642), and National major projects of genetically modified organisms breeding (2018ZX08010-08B), and Project of National Natural Science Foundation of China (31872580), and Project of Marine Fishery Science and Technology of Guangdong Province (GDME-2018C012), and Natural Science Foundation of Guangdong Province (2017A030313195), and Project of Science and Technology of Guangzhou City (201803020006), Project of Science and Technology of Guangdong Province (2019B110209005), and Guangdong Provincial Special Fund for Morden Agriculture Industry Technology Innovation Teams (2019KJ143), Key-Area Research and Development Program of Guangdong Province (2019B110209005). Joint fund for basic and applied research of Guangdong Province (2019A1515110068). The authors thank the participants who gave their time to the trial.

Acknowledgments: All authors worked in unity and harmony. The authors would like to express their gratitude to EditSprings (https://www.editsprings.com/) for the expert linguistic services provided.

Conflicts of Interest: The authors declare no conflict of interest. The funders had no role in the design of the study; in the collection, analyses, or interpretation of data; in the writing of the manuscript, or in the decision to publish the results.

\section{References}

1. Albrektsen, S.; Østbye, T.-K.; Pedersen, M.; Ytteborg, E.; Ruyter, B.; Ytrestøyl, T. Dietary impacts of sulphuric acid extracted fish bone compounds on astaxanthin utilization and muscle quality in Atlantic salmon (Salmo salar). Aquaculture 2018, 495, 255-266. [CrossRef]

2. Mattei, R.; Polotow, T.G.; Vardaris, C.V.; Guerra, B.A.; Leite, J.R.; Otton, R.; Barros, M.P. Astaxanthin limits fish oil-related oxidative insult in the anterior forebrain of Wistar rats: Putative anxiolytic effects? Pharmacol. Biochem. Behav. 2011, 99, 349-355. [CrossRef] [PubMed]

3. Al-Amin, M.M.; Reza, H.M.; Saadi, H.M.; Mahmud, W.; Ibrahim, A.A.; Alam, M.M.; Kabir, N.; Saifullah, A.R.M.; Tropa, S.T.; Quddus, A.H.M.R. Astaxanthin ameliorates aluminum chloride-induced spatial memory impairment and neuronal oxidative stress in mice. Eur. J. Pharmacol. 2016, 777, 60-69. [CrossRef] [PubMed]

4. Kim, J.H.; Chang, M.J.; Choi, H.D.; Youn, Y.-K.; Kim, J.T.; Oh, J.M.; Shin, W.G. Protective effects of Haematococcus astaxanthin on oxidative stress in healthy smokers. J. Med. Food 2011, 14, 1469-1475. [CrossRef] [PubMed]

5. Chien, Y.H.; Pan, C.H.; Hunter, B. The resistance to physical stresses by Penaeus monodon juveniles fed diets supplemented with astaxanthin. Aquaculture 2003, 216, 177-191. [CrossRef]

6. Zhang, J.; Liu, Y.-J.; Tian, L.-X.; Yang, H.-J.; Liang, G.-Y.; Yue, Y.-R.; Xu, D.-H. Effects of dietary astaxanthin on growth, antioxidant capacity and gene expression in Pacific white shrimp Litopenaeus vannamei. Aquac. Nutr. 2013, 19, 917-927. [CrossRef]

7. Song, X.; Wang, L.; Li, X.; Chen, Z.; Liang, G.; Leng, X. Dietary astaxanthin improved the body pigmentation and antioxidant function, but not the growth of discus fish (Symphysodon spp.). Aquac. Res. 2017, 48, 1359-1367. [CrossRef]

8. Lim, K.C.; Yusoff, F.M.; Shariff, M.; Kamarudin, M.S. Dietary administration of astaxanthin improves feed utilization, growth performance and survival of Asian seabass, Lates calcarifer (Bloch, 1790). Aquac. Nutr. 2019, 25, 1410-1421. [CrossRef] 
9. Lam, H.S.; Ngoc, P.T. Effect of dietary astaxanthin on pigment accumulation in the muscle-skin, resistance to salinity and copper toxicity of commercial clownfish, Amphiprion ocellaris. Vietnam J. Mar. Sci. Technol. 2018, 18, 60-69.

10. Niu, J.; Tian, L.X.; Liu, Y.J.; Yang, H.J.; Ye, C.X.; Gao, W.; Mai, K. Sen Effect of dietary astaxanthin on growth, survival, and stress tolerance of postlarval shrimp, Litopenaeus vannamei. J. World Aquac. Soc. 2009, 40, 795-802. [CrossRef]

11. Cheng, C.-H.; Guo, Z.-X.; Ye, C.-X.; Wang, A.-L. Effect of dietary astaxanthin on the growth performance, non-specific immunity, and antioxidant capacity of pufferfish (Takifugu obscurus) under high temperature stress. Fish Physiol. Biochem. 2018, 44, 209-218. [CrossRef] [PubMed]

12. Mourente, G.; Diaz-Salvago, E.; Bell, J.G.; Tocher, D.R. Increased activities of hepatic antioxidant defence enzymes in juvenile gilthead sea bream (Sparus aurata L.) fed dietary oxidised oil: Attenuation by dietary vitamin E. Aquaculture 2002, 214, 343-361. [CrossRef]

13. Frankel, E.N. Lipid oxidation. Prog. Lipid Res. 1980, 19, 1-22. [CrossRef]

14. Howell, B.R.; Day, O.J.; Ellis, T.; Baynes, S.M. Early life stages of farmed fish. In Biology of Farmed Fish; Black, K.D., Pickering, A.D., Eds.; Academic Press: Sheffield, UK, 1998; pp. 27-66.

15. Hamre, K. Metabolism, interactions, requirements and functions of vitamin E in fish. Aquac. Nutr. 2011, 17, 98-115. [CrossRef]

16. Kanazawa, K. Hepatotoxicity caused by dietary secondary products originating from lipid peroxidation. In Nutritional and Toxicological Consequences of Food Processing; Springer: Boston, MA, USA, 1991; pp. 237-253.

17. Hang, T.N.A. Effects of Dietary Oxidation Status and Vitamin E Level on Performance, Fillet Quality and Robustness to Acute Stress in Atlantic Salmon (Salmo salar L.); Norwegian University of Life Sciences: Ås, Norway, 2012.

18. Chen, S.; Zhuang, Z.; Yin, P.; Chen, X.; Zhang, Y.; Tian, L.; Niu, J.; Liu, Y. Changes in growth performance, haematological parameters, hepatopancreas histopathology and antioxidant status of pacific white shrimp (Litopenaeus vannamei) fed oxidized fish oil: Regulation by dietary myo-inositol. Fish Shellfish Immunol. 2019, 88, 53-64. [CrossRef]

19. Fontagné-Dicharry, S.; Larroquet, L.; Dias, K.; Cluzeaud, M.; Heraud, C.; Corlay, D. Effects of dietary oxidized fish oil supplementation on oxidative stress and antioxidant defense system in juvenile rainbow trout (Oncorhynchus mykiss). Fish Shellfish Immunol. 2018, 74, 43-51. [CrossRef]

20. Yin, P.; Xie, S.; Huo, Y.; Guo, T.; Fang, H.; Zhang, Y.; Liu, Y.; Tian, L.; Niu, J. Effects of dietary oxidized fish oil on growth performance, antioxidant defense system, apoptosis and mitochondrial function of juvenile largemouth bass (Micropterus salmoides). Aquaculture 2019, 500, 347-358. [CrossRef]

21. Zhong, Y.; Lall, S.P.; Shahidi, F. Effects of oxidized dietary oil and vitamin E supplementation on lipid profile and oxidation of muscle and liver of juvenile Atlantic cod (Gadus morhua). J. Agric. Food Chem. 2007, 55, 6379-6386. [CrossRef]

22. Koshio, S.; Teshima, S.; Kanazawa, A. Effects of dietary oxidized oil for Penaeus japonicus. Fish. Sci. 1994, 60, 283-288. [CrossRef]

23. Laohabanjong, R.; Tantikitti, C.; Benjakul, S.; Supamattaya, K.; Boonyaratpalin, M. Lipid oxidation in fish meal stored under different conditions on growth, feed efficiency and hepatopancreatic cells of black tiger shrimp (Penaeus monodon). Aquaculture 2009, 286, 283-289. [CrossRef]

24. Wang, L.G.; Li, E.C.; Qin, J.G.; Du, Z.Y.; Yu, N.; Kong, Y.Q.; Feng, D.X.; Chen, L.Q. Effect of oxidized fish oil and $\$ \alpha \$$-tocopherol on growth, antioxidation status, serum immune enzyme activity and resistance to $\mathrm{A}$ eromonas hydrophila challenge of Chinese mitten crab Eriocheir sinensis. Aquac. Nutr. 2015, 21, 414-424. [CrossRef]

25. Sirirustananun, N.; Chen, J.C.; Lin, Y.C.; Yeh, S.T.; Liou, C.H.; Chen, L.L.; Sim, S.S.; Chiew, S.L. Dietary administration of a Gracilaria tenuistipitata extract enhances the immune response and resistance against Vibrio alginolyticus and white spot syndrome virus in the white shrimp Litopenaeus vannamei. Fish Shellfish Immunol. 2011, 31, 848-855. [CrossRef] [PubMed]

26. Flegel, T.W. Major viral diseases of the black tiger prawn (Penaeus monodon) in Thailand. World J. Microbiol. Biotechnol. 1997, 13, 433-442. [CrossRef]

27. Fontagné, S.; Bazin, D.; Brèque, J.; Vachot, C.; Bernarde, C.; Rouault, T.; Bergot, P. Effects of dietary oxidized lipid and vitamin A on the early development and antioxidant status of Siberian sturgeon (Acipenser baeri) larvae. Aquaculture 2006, 257, 400-411. [CrossRef] 
28. Dong, G.F.; Huang, F.; Zhu, X.M.; Zhang, L.; Mei, M.X.; Hu, Q.W.; Liu, H.Y. Nutriphysiological and cytological responses of juvenile channel catfish (Ictalurus punctatus) to dietary oxidized fish oil. Aquac. Nutr. 2012, 18, 673-684. [CrossRef]

29. Sánchez-Muniz, F.J.; López-Varela, S.; Garrido-Polonio, M.C.; Cuesta, C. Dietary effects on growth, liver peroxides, and serum and lipoprotein lipids in rats fed a thermoxidised and polymerised sunflower oil. J. Sci. Food Agric. 1998, 76, 364-372. [CrossRef]

30. Lewis-McCrea, L.M.; Lall, S.P. Effects of moderately oxidized dietary lipid and the role of vitamin E on the development of skeletal abnormalities in juvenile Atlantic halibut (Hippoglossus hippoglossus). Aquaculture 2007, 262, 142-155. [CrossRef]

31. Fontagné, S.; Lataillade, E.; Breque, J.; Kaushik, S. Lipid peroxidative stress and antioxidant defence status during ontogeny of rainbow trout (Oncorhynchus mykiss). Br. J. Nutr. 2008, 100, 102-111. [CrossRef]

32. Fatima, M.; Afzal, M.; Shah, S.Z.H. Effect of dietary oxidized oil and vitamin E on growth performance, lipid peroxidation and fatty acid profile of Labeo rohita fingerlings. Aquac. Nutr. 2019, 25, 281-291. [CrossRef]

33. Gao, J.; Koshio, S.; Ishikawa, M.; Yokoyama, S.; Nguyen, B.T.; Mamauag, R.E. Effect of dietary oxidized fish oil and vitamin $C$ supplementation on growth performance and reduction of oxidative stress in Red Sea Bream Pagrus major. Aquac. Nutr. 2013, 19, 35-44. [CrossRef]

34. Chen, Y.J.; Liu, Y.J.; Tian, L.X.; Niu, J.; Liang, G.; Yang, H.; Yuan, Y.; Zhang, Y.Q. Effect of dietary vitamin $\mathrm{E}$ and selenium supplementation on growth, body composition, and antioxidant defense mechanism in juvenile largemouth bass (Micropterus salmoide) fed oxidized fish oil. Fish Physiol. Biochem. 2013, 39, 593-604. [CrossRef]

35. Yang, S.-P.; Liu, H.-L.; Wang, C.-G.; Yang, P.; Sun, C.-B.; Chan, S.-M. Effect of oxidized fish oil on growth performance and oxidative stress of Litopenaeus vannamei. Aquac. Nutr. 2015, 21, 121-127. [CrossRef]

36. Wang, Z.; Cai, C.; Cao, X.; Zhu, J.; He, J.; Wu, P.; Ye, Y. Supplementation of dietary astaxanthin alleviated oxidative damage induced by chronic high $\mathrm{pH}$ stress, and enhanced carapace astaxanthin concentration of Chinese mitten crab Eriocheir sinensis. Aquaculture 2018, 483, 230-237. [CrossRef]

37. Niu, J.; Li, C.H.; Liu, Y.J.; Tian, L.X.; Chen, X.; Huang, Z.; Lin, H.Z. Dietary values of astaxanthin and canthaxanthin in Penaeus monodon in the presence and absence of cholesterol supplementation: Effect on growth, nutrient digestibility and tissue carotenoid composition. Br. J. Nutr. 2012, 108, 80-91. [CrossRef]

38. Segner, H.; Arend, P.; Von Poeppinghausen, K.; Schmidt, H. The effect of feeding astaxanthin to Oreochromis niloticus and Colisa labiosa on the histology of the liver. Aquaculture 1989, 79, 381-390. [CrossRef]

39. Wang, W.; Ishikawa, M.; Koshio, S.; Yokoyama, S.; Dawood, M.A.O.; Hossain, M.S.; Moss, A.S. Effects of dietary astaxanthin and vitamin $\mathrm{E}$ and their interactions on the growth performance, pigmentation, digestive enzyme activity of kuruma shrimp (Marsupenaeus japonicus). Aquac. Res. 2019, 50, 1186-1197. [CrossRef]

40. Li, M.-Y.; Gao, C.-S.; Du, X.-Y.; Zhao, L.; Niu, X.-T.; Wang, G.-Q.; Zhang, D.-M. Effect of sub-chronic exposure to selenium and astaxanthin on Channa argus: Bioaccumulation, oxidative stress and inflammatory response. Chemosphere 2020, 244, 125546. [CrossRef]

41. Chien, Y.H.; Shiau, W.C. The effects of dietary supplementation of algae and synthetic astaxanthin on body astaxanthin, survival, growth, and low dissolved oxygen stress resistance of kuruma prawn, Marsupenaeus japonicus Bate. J. Exp. Mar. Bio. Ecol. 2005, 318, 201-211. [CrossRef]

42. Pan, C.H.; Chien, Y.H.; Hunter, B. The resistance to ammonia stress of Penaeus monodon Fabricius juvenile fed diets supplemented with astaxanthin. J. Exp. Mar. Bio. Ecol. 2003, 297, 107-118. [CrossRef]

43. Chen, Y.J.; Liu, Y.J.; Yang, H.J.; Yuan, Y.; Liu, F.J.; Tian, L.X.; Liang, G.Y.; Yuan, R.M. Effect of dietary oxidized fish oil on growth performance, body composition, antioxidant defence mechanism and liver histology of juvenile largemouth bass Micropterus salmoides. Aquac. Nutr. 2012, 18, 321-331. [CrossRef]

44. Bhavan, P.S.; Geraldine, P. Histopathology of the hepatopancreas and gills of the prawn Macrobrachium malcolmsonii exposed to endosulfan. Aquat. Toxicol. 2000, 50, 331-339. [CrossRef]

45. Caceci, T.; Neck, K.F.; Lewis, D.D.H.; Sis, R.F. Ultrastructure of the hepatopancreas of the pacific white shrimp, Penaeus vannamei (Crustacea: Decapoda). J. Mar. Biol. Assoc. 1988, 68, 323-337. [CrossRef]

46. Bautista, M.N.; Lavilla-Pitogo, C.R.; Subosa, P.F.; Begino, E.T. Aflatoxin B1 contamination of shrimp feeds and its effect on growth and hepatopancreas of pre-adult Penaeus monodon. J. Sci. Food Agric. 1994, 65, 5-11. [CrossRef]

47. National Research Council. Nutrient Requirements of Fish and Shrimp; National Academies Press: Washington, DC, USA, 2011. 
48. Yu, Y.Y.; Chen, S.J.; Chen, M.; Tian, L.X.; Niu, J.; Liu, Y.J.; Xu, D.H. Effect of cadmium-polluted diet on growth, salinity stress, hepatotoxicity of juvenile Pacific white shrimp (Litopenaeus vannamei): Protective effect of Zn(II)-curcumin. Ecotoxicol. Environ. Saf. 2016, 125, 176-183. [CrossRef]

49. Yuan, J.P.; Gong, X.D.; Chen, F. Separation and identification of astaxanthin esters and chlorophylls in haematococcus lacustris by HPLC. Biotechnol. Tech. 1996, 10, 655-660. [CrossRef]

50. Esterbauer, H.; Cheeseman, K.H. Determination of aldehydic lipid peroxidation products: Malonaldehyde and 4-hydroxynonenal. In Methods in Enzymology; Lester Packer, A.N.G., Ed.; Academic Press: Cambridge, MA, USA, 1990; pp. 407-421.

(C) 2020 by the authors. Licensee MDPI, Basel, Switzerland. This article is an open access article distributed under the terms and conditions of the Creative Commons Attribution (CC BY) license (http://creativecommons.org/licenses/by/4.0/). 